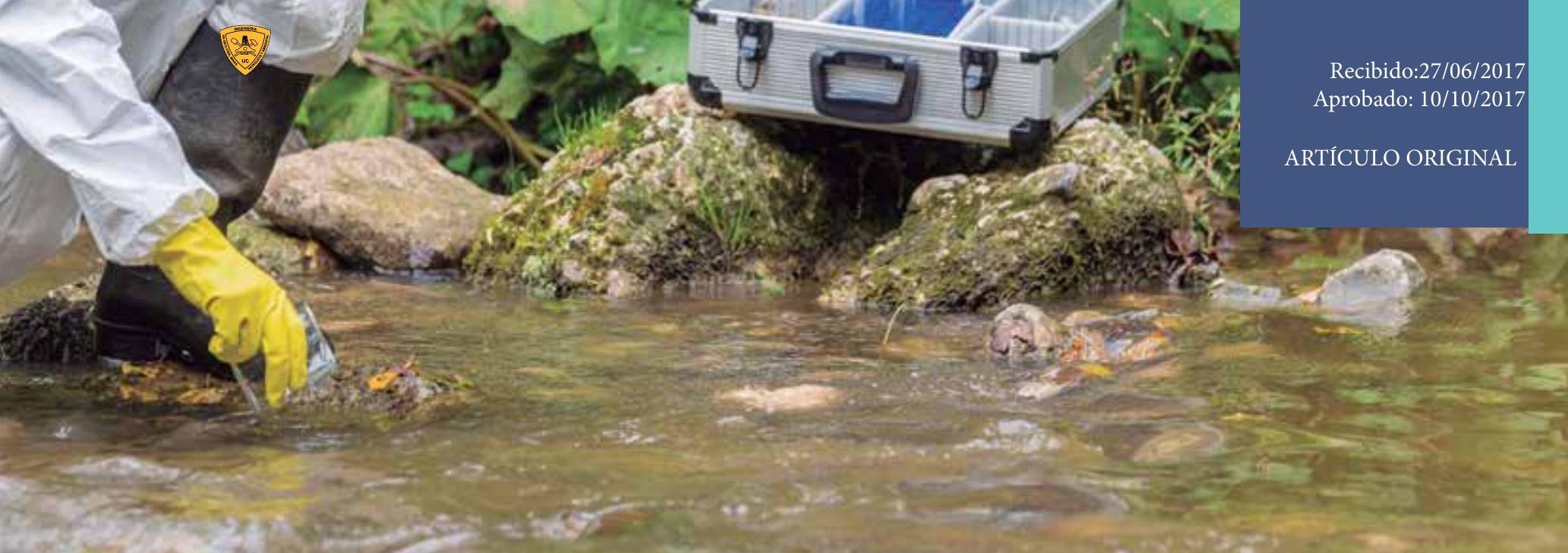

\title{
Política minera y sostenibilidad ambiental en Ecuador
}

\section{Mining policy and environmental sustainability in Ecuador}

Rea Toapanta, Antonio Ricardo

Docente Ciencias Económicas

Universidad Central del Ecuador

arrea@uce.edu.ec / antonio_ricardo_rea@yahoo.com

\section{Resumen}

En el Ecuador de hoy, históricamente, en las provincias de Manabí y Esmeraldas en la Costa; Azuay y Cañar en la Sierra, fueron las que más desarrollaron la minería. En las décadas de los 80s y 90s la Misión Británica realizó trabajos de investigación geológica en las cordilleras Oriental (Real) y Occidental, concluyendo con la publicación de mapas a diferentes escalas. Las competencias del Ministerio Sectorial son ejercer la rectoría de las políticas públicas del área geológico-minera, expedir los acuerdos y resoluciones administrativas que requiera su gestión; evaluar las políticas, planes y proyectos para el desarrollo del sector minero; definir en coordinación con la entidad rectora de la planificación nacional, el Plan Nacional de Desarrollo del Sector Minero. La Ley de Minería, vigente desde enero de 2009, estableció una nueva institucionalidad, conformada por: Ministerio Sectorial (Ministerio de Recursos Naturales No Renovables), considerando La Minería Artesanal y La pequeña Minería. Para 2012, Ecuador inició actividades mineras a gran escala. El Gobierno ecuatoriano, a través de la Secretaría Nacional de Planificación y Desarrollo (SENPLADES), definió cinco proyectos mineros estratégicos: Fruta del Norte, Mirador, Proyecto concesionado a la empresa Lam Gold, Río Blanco y Panantza San Carlos. Previo a su explotación, los concesionarios de estos proyectos deben firmar con el Estado un contrato de explotación minera. El aspecto ambiental considera: Impacto directo o indirecto sobre el medio. Según sea el efecto; a corto o largo plazo. Sea reversible o irreversible. Los cinco proyectos, más el proyecto Llurimagua, ubicado en Imbabura, deberían atraer inversiones por cerca de USD 8000 millones hasta 2024, presentándose un optimismo de la industria minera, pero los desafíos están en mitigar los impactos ambientales y capacitar la mano de obra productiva.

Palabras clave: política minera; sostenibilidad ambiental; ecuador.

\section{Abstract}

In today's Ecuador, historically, in the provinces of Manabi and Esmeraldas on the Coast; Azuay and Cañar in the Sierra, were the most developed mining. In the decades of the 80s and 90s, the British Mission performed geological research in the Eastern (Real) and Western Ranges, concluding with the publication of maps at different scales. The competencies of the Sector Ministry are to exercise the rectory of the public policies of the geological-mining area, to issue the administrative agreements and resolutions that require their management; Evaluate policies, plans and projects for the development of the mining sector; Define, in coordination with the governing body of national planning, the National Development Plan for the Mining Sector. The Mining Law, in force since January 2009, established a new institutional structure, made up of: Sector Ministry (Ministry of Non Renewable Natural Resources), considering Artisanal Mining and Smallscale Mining. For 2012, Ecuador initiated large-scale mining activities. 
The Ecuadorian Government, through the National Secretariat for Planning and Development (SENPLADES), defined five strategic mining projects: Fruta del Norte, Mirador, Project awarded to the company Lam Gold, Río Blanco and Panantza San Carlos. Prior to their exploitation, concessionaires of these projects must sign a mining contract with the State. The environmental aspect considers: Direct or indirect impact on the environment. Depending on the effect; Short or long term. Be reversible or irreversible. The five projects, plus the Llurimagua project, located in Imbabura, should attract investments of about USD 8 billion up to 2024, presenting optimism for the mining industry, but the challenges are in mitigating environmental impacts and training productive labor.

Keywords: mining policy; environmental sustainability; ecuador

\section{Introducción}

Las actividades productivas y de conservación de los recursos naturales, deben manejarse en el marco de equilibrio de utilidad racional entre hombre y naturaleza; mediante la influencia de las llamadas Dimensiones Económicas, Sociales y Ambientales. Lo anterior se gestiona mediante las ciencias aplicadas tanto técnicas como sociales, considerando la Minería, la Economía Ambiental y Ecológica; que se conjugue en el desarrollo económico y la Sostenibilidad, siendo beneficiarios la Sociedad y la Naturaleza.

\section{Antecedentes del Ecuador minero}

La minería en Ecuador, se explotó desde tiempos pre histórico. Antes de la época pre colonial, las comunidades de entonces, ya explotaban la obsidiana de Mullumica y las arcillas para la cerámica, trabajaron el oro, la plata, el cobre y el platino para ornamentos, rituales e intercambio comercial, extrayéndolos de ríos y socavones.

Las culturas prehispánicas asentadas en el Ecuador de hoy, sobre todo en las actuales provincias de Manabí y Esmeraldas en la Costa, Azuay y Cañar en la Sierra, fueron las que más desarrollaron la minería.

En Esmeraldas, entre los años 500 antes de Cristo y 500 después de Cristo, los habitantes de la Cultura Tolita trabajaron el oro y platino. Un ejemplo es la máscara de platino elaborado por esta cultura. Los "Cañaris" también labraron con perfección el oro y la plata. Una muestra de esta metalurgia antigua es la máscara de oro, encontrada en 1940 en Chunucari, cercano al cantón Sigsig, siendo adoptada como emblema del Banco Central del Ecuador. (Museo del Banco Central del Ecuador). (Universo, 2002)

Los nativos del Imperio Inca, ofrendaban al Dios Sol entre otras riquezas el Kuri (oro), metal que no tenía ningún valor nominal, pero que era utilizado para ofrendas sagradas, utensilios de belleza y hasta de carácter doméstico. También explotaban el mercurio o azogue.

La presencia de los españoles en América (1492) y años más tarde en lo que ahora es Ecuador, marcó un hito en la historia minera. Una parte de ella, narra que el cacique Quinnara condujo a millares de aborígenes a Cajamarca llevando oro para pagar el rescate de Atahualpa, prisionero de los españoles.

Esto, y el descubrimiento de pequeñas partículas de oro en las arenas de los ríos, impulsaron a los buscadores a remontar ríos y montañas hasta llegar al sitio desde donde se desprendían las pepitas doradas. Corría mediados del siglo XVI.

Las áreas mineras fueron: Zaruma; luego Portovelo. Por esa época también se descubrió el yacimiento de Nambija, distritos que hasta la actualidad están entre los más importantes sitios mineros.

Al calor de la fiebre del oro se fundaron las ciudades de Loja (1548, segunda fundación), Zamora (1549), Jaén (1549), Cuenca (1557), Valladolid (1557) y Sevilla de Oro (1575).

Portovelo fue explotada desde fines del siglo XIX hasta mediados del siglo XX por la compañía South American Development Company, más conocida como SADCO, que también creó la Cotopaxi Exploration Company para explotar el yacimiento de Macuchi.

Al salir SADCO de Portovelo, se creó la Compañía Industrial Minera Asociada (CIMA) que trabajó hasta la década de los 70, dejando la explotación en manos de pequeños mineros y artesanos.

En los años /80s del siglo XX, se redescubrió Nambija y se descubrió los yacimientos de Ponce Enríquez y Cerro Pelado - Los Ingleses, que son explotados hasta la actualidad.

Posteriormente en las décadas de los 80s y 90s la Misión Británica realizó trabajos de investigación 
geológica en las cordilleras Oriental (Real) y Occidental, concluyendo con la publicación de mapas a diferentes escalas y la identificación de nuevas zonas prospectivas.

En la actualidad el Instituto Nacional de Investigación Geológico-Minero-Metalúrgico (Inigemm) tiene como competencia generar, sistematizar, focalizar y administrar la información geológica en todo el territorio nacional, para promover el desarrollo sostenible y sustentable de los recursos minerales y prevenir la Incidencia de las amenazas geológicas y aquellas ocasionadas por el hombre en apoyo al Ordenamiento Territorial.

\section{Diagnóstico, estado de la cuestión, exposición detallada del caso}

\section{Minerales en Ecuador}

En el Ecuador existen minerales metálicos y no metálicos.

Los primeros son minerales de bajo volumen de concentración y alto valor económico. Entre los más importantes están el oro, la plata, el cobre, el plomo y el zinc.

Los no metálicos son minerales de alto volumen de concentración y poco valor económico. Entre los más importantes están el azufre, el yeso, la caliza, el feldespato y la arena silícea.

Las diferentes regiones del país tienen varios minerales. Por ejemplo en el Austro existen oro, plata, cobre, plomo y zinc, además de materias primas minerales para producir diferentes tipos de cerámica, producto que durante el tiempo le ha dado renombre a esa región del país.

Además, existen materias primas para la producción de cemento, vidrio plano y derivados, rocas ornamentales y mármol, aguas termales, caolines, yeso, arenas silíceas, entre otros.

El sur del país representa un alto potencial para la búsqueda de minerales metálicos como oro, plata, cobre, plomo y zinc, y otras materias primas de minerales no metálicos para producir diferentes tipos de cerámica, cemento, vidrio plano y derivados; además de rocas ornamentales y mármoles; también existen aguas termales, caolines, yeso, arenas silíceas, entre otros.

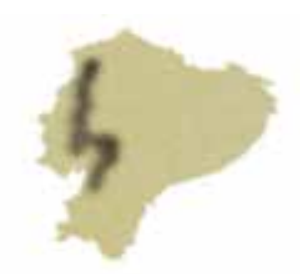

La regibn de a costa se caracterua por is presenca oe minerates ne metalicos y ctaceres auiteros (cen on tas roeras oe ins rios).

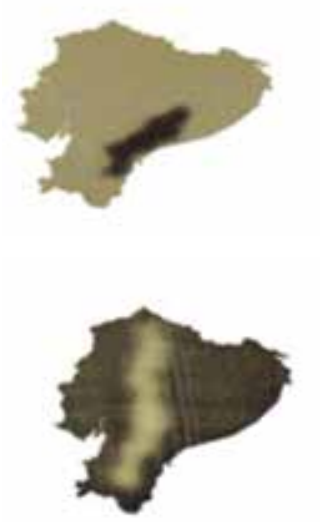

ta regibn Amazonica tambien posee reservas de oro, plata, cobre, antimonio y reales expectativas de plomo, zincy arenas siliceas.

Figura 1 Yacimientos en Ecuador. Fuente SENPLADES

\section{Nuevo marco institucional}

La Ley de Minería, vigente desde enero de 2009, estableció una nueva institucionalidad, conformada por:

Ministerio Sectorial (Ministerio de Recursos Naturales No Renovables)

Viceministerio de Minas

Subsecretaría Nacional de Desarrollo Minero

Subsecretaría Nacional de Contratación Minera

Subsecretaría Regional de Minas Norte (zonas 1 y 2)

Subsecretaría Regional de Minas Centro (zona 3)

Subsecretaría Regional de Minas Litoral (zonas 4 y 5)

Subsecretaría Regional de Minas Centro Sur (zona 6)

Subsecretaría Regional de Minas Sur (zona 7)

Agencia de Regulación y Control Minero (ARCOM)

Instituto Nacional de Investigación Geológico Minero Metalúrgico (Inigemm)

Empresa Nacional Minera (ENAMIEP)

\section{Ministerio sectorial}

Es el órgano rector y planificador del sector minero. Le corresponde la aplicación de políticas, directrices y planes. 
Las competencias del Ministerio Sectorial son ejercer la rectoría de las políticas públicas del área geológico-minera, expedir los acuerdos y resoluciones administrativas que requiera su gestión; evaluar las políticas, planes y proyectos para el desarrollo, administración, regulación y gestión del sector minero; ejecutar, de manera desconcentrada, la política pública definida para el desarrollo del sector; promover en coordinación con instituciones públicas y o privadas, universidades y escuelas politécnicas, la investigación científica y tecnológica en el sector minero; definir, en coordinación con la entidad rectora de la planificación nacional, el Plan Nacional de Desarrollo del Sector Minero.

También le compete supervisar el cumplimiento de los objetivos, las políticas y las metas definidas para el sector que ejecutan las personas naturales y jurídicas públicas y privadas; establecer los parámetros e indicadores para el seguimiento, supervisión y evaluación de la gestión de las empresas públicas e informar al Ejecutivo sobre los resultados de tal ejecución y medición; otorgar, administrar y extinguir los derechos mineros.

\section{Agencia de regulación y control minero (ARCOM)}

Organismo técnico - administrativo, encargada de auditar, Intervenir y controlar las fases de la actividad minera que realice la Empresa Nacional Minera, las empresas mixtas mineras, la iniciativa privada, la pequeña minería, minería artesanal y de sustento.

\section{니니 Instituto Nacional de Investigación Geológico Minero} Metalúrgico (INIGEMM)

Institución pública encargada de realizar actividades de investigación, desarrollo tecnológico e innovación en materia Geológica, Minera y Metalúrgica; tiene competencia para generar, sistematizar, focalizar y administrar la información geológica en todo el territorio nacional, para promover el Desarrollo Sostenible y Sustentable de los recursos minerales y prevenir la incidencia de las amenazas geológicas y aquellas ocasionadas por el hombre, en apoyo al Ordenamiento Territorial.

\section{Empresa Nacional Minera (ENAMI EP)}

Sociedad de derecho público, destinada a la gestión de la actividad minera para el aprovechamiento sustentable de los recursos. Sujeta a la regulación y control establecido en la Ley de Empresas Públicas. Para el cumplimiento de sus fines, podrá asociarse, constituir compañías de economía mixta, celebrar asociaciones, uniones transitorias y alianzas estratégicas.

Tiene a su cargo los proyectos mineros comunitarios en Selva Alegre (Esmeraldas) y en Congüime (Zamora Chinchipe), donde se erradicó la minería ilegal y el Ministerio de Recursos Naturales No Renovables concesionó las áreas a la ENAMI EP para que, luego de organizar a los pobladores, conformen sociedades y exploten el mineral (oro básicamente). También los proyectos Isimanchi, La Tronera y Toa, con potenciales reservas de calizas y sílice, así como los proyectos auríferos Pacto, Portovelo, Congüime y Río Santiago.

\section{Actividad minera en Ecuador}

En el país se ha desarrollado la minería, sólo a nivel de minería artesanal y de pequeña minería. En los dos casos, el Gobierno capacita a los mineros, apoya en su regularización y les da asistencia técnica; además de que está promulgando la Ley de Fomento, Participación y Capacitación de la Pequeña Minería y Minería Artesanal.

\section{Minería artesanal}

La minería artesanal es la que se efectúa mediante trabajo individual, familiar o asociativo de quien realiza actividades mineras autorizadas por el Estado; se caracteriza por la utilización de herramientas, máquinas simples y portátiles destinadas a la obtención de minerales. La venta de éstos sólo permite cubrir las necesidades básicas de la persona o del grupo familiar que las realice, y que no hayan requerido una inversión superior a las 150 remuneraciones básicas unificadas.

En caso de producirse la asociación de tres o más mineros artesanales, su inversión será de 300 remuneraciones básicas unificadas y previo Informe técnico, económico, social y ambiental de la Agencia de Regulación y Control Minero. Para el trabajo en minería artesanal, el Ministerio Sectorial entrega permisos de hasta 10 años, que será renovado por periodos iguales, siempre que exista petición escrita antes de su vencimiento y que tenga informe favorable de la Agencia de Regulación y Control y del Ministerio del Ambiente. Los mineros artesanales no pagan regalías.

Labores mineras artesanales: 700 regularizadas con los acuerdos ministeriales elaborados.

Producción anual de oro, estimada: una tonelada. 
Empleo generado (directo e indirecto): 30.000 .

La mayor cantidad de labores mineras artesanales están en las provincias de Zamora Chinchipe y EI Oro.

\section{Pequeña minería}

Es aquella que, en razón del área de las concesiones, volumen de producción y procesamiento, monto de inversiones y condiciones tecnológicas, tiene:

Una capacidad instalada de explotación y/o beneficio de hasta 300 toneladas métricas por día.

Una capacidad de producción de hasta 800 metros cúbicos por día, con relación a la minería de no metálicos y materiales de construcción.

Las personas naturales o jurídicas que realicen pequeña minería deberán ser titulares de una concesión minera (área asignada por el Estado). El Ministerio Sectorial promoverá programas especiales de asistencia técnica, de manejo ambiental, de seguridad minera y de capacitación y formación profesional a la pequeña minería. El Ministerio del Ambiente, también promoverá programas especiales de manejo ambiental en la pequeña minería.

Concesiones de pequeña minería: 290 calificadas y 750 aproximadamente en proceso de calificación.

Producción estimada: 10 toneladas de oro al año; Empleo (directo e indirecto): 100.000 personas.

La pequeña minería se desarrolla principalmente en los distritos mineros Portovelo, Zaruma, Minas Nuevas, Ponce Enríquez, Nambija, Chinapintza, Pacto, El Corazón, Alao, Toachi, Macuchi, Cumandá Cariamanga y Célica, entre otros lugares en menor proporción.

Además, se ha encontrado minería ilegal en Esmeraldas, Pastaza, Ñapo y Zamora Chinchipe, labor que el Gobierno combate, porque actúa al margen de la ley, causando perjuicios económicos y ambientales.

\section{La nueva era minera}

Antes del Mandato Constituyente No. 6, emitido por la Asamblea Constituyente en abril de 2008, existían 4.341 concesiones mineras. Por la aplicación de este Mandato se archivaron 1.334 concesiones, y por otras causas 956; sobrevivieron 2.051 que, según la Ley de Minería (aprobada en enero de 2009) debían sustituir sus títulos hasta el 10 de mayo de 2010. De ese total, 1.484 concesionarios mineros cumplieron con la disposición, y para mantenerse vigentes deben estar al día en sus obligaciones con el Estado ecuatoriano.

Entre los concesionarios que sustituyeron los títulos, constan proyectos considerados a gran escala, que tienen reservas de oro, plata, cobre y otros minerales, y que estuvieron concesionados con anterioridad al Gobierno de Rafael Correa Delgado (enero de 2007).

Para 2012, Ecuador está a las puertas de iniciar actividades mineras a gran escala, segmento en el que el país no tiene mayor experiencia y por ello es necesaria la presencia de empresas extranjeras con tecnología de punta.

Sin embargo, éstas podrán explotar minerales en Ecuador, siempre y cuando firmen contratos de explotación minera, donde conste aspectos como el pago de una regalía (porcentaje de las ganancias obtenidas por la venta de su producción), las obligaciones a cumplir, así como las sanciones en caso de causar inconvenientes a la sociedad y al ambiente.

\section{Proyectos estratégicos}

El Gobierno ecuatoriano, a través de la Secretaría Nacional de Planificación y Desarrollo (SENPLADES), definió cinco proyectos mineros estratégicos: Fruta del Norte, Mirador, el proyecto concesionado a la empresa Lam Gold, Río Blanco y Panantza San Carlos. Previo a su explotación, los concesionarios de estos proyectos deben firmar con el Estado un contrato de explotación minera.

\section{Proyectos estratégico en el Ecuador}

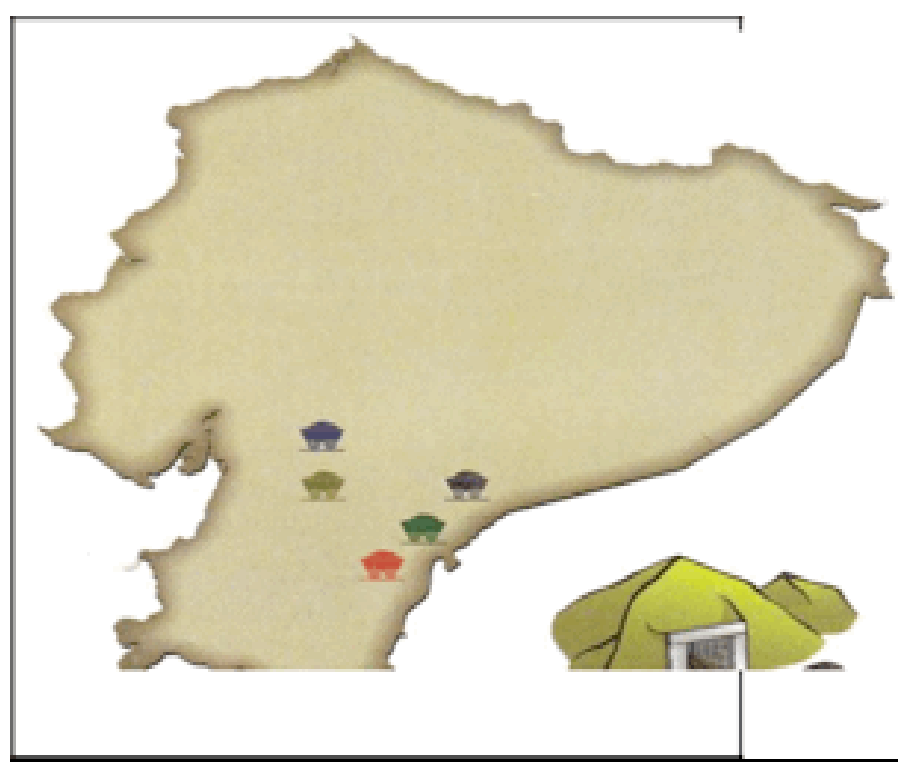

Figura 2. Proyectos Estratégicos en el Ecuador. Fuente: SENPLADES 
Fruta del Norte: ubicado en la provincia de Zamora Chinchipe, parroquia Los Encuentros. Está concesionado a la compañía Kinross-Aurelian. Tiene reservas de oro principalmente.

Mirador: ubicado en la Provincia de Zamora Chinchipe, cantón El Pangui. Está concesionado a la empresa Ecua Corriente Sociedad Anónima (ECSA). Posee reservas de cobre.

Río Blanco: ubicado en la provincia de Azuay, entre las parroquias Chaucha y Molleturo. Tiene reservas de oro. Concesionado a la empresa San Luis Minerals.

El proyecto de la compañía lam Gold Ecuador S.A., localizado en la provincia de Azuay, más arriba de las parroquias San Gerardo y Chumblin. Tiene reservas de oro y plata.

Panantza San Carlos: concesionado a la empresa Ecua Corriente S.A. ECSA. Está ubicado en la provincia de Morona Santiago, cantón San Juan Bosco. Tiene reservas de cobre. Estos proyectos están considerados como estratégicos porque ayudarán a crear enclaves de desarrollo económico y a mejorar las condiciones de vida de las personas de zonas históricamente olvidadas, como Zamora Chinchipe, Morona Santiago. "Montos por confirmarse luego de la negociación de los contratos de explotación minera.

\section{Tabla 1. Inversión prevista en proyectos}

\begin{tabular}{|c|c|c|c|c|}
\hline Empresa & Proyecto & Origen & $\begin{array}{l}\text { Mineral } \\
\text { Principal }\end{array}$ & $\begin{array}{l}\text { Inversión MM } \\
\text { USD } \\
\text { Estimada al } \\
\mathbf{2 0 1 6}\end{array}$ \\
\hline ECSA & Mirador & China & Cobre & 1.634 \\
\hline $\begin{array}{l}\text { Kinross } \\
\text { Aurelian }\end{array}$ & $\begin{array}{l}\text { Fruta del } \\
\text { Norte }\end{array}$ & Canadá & Oro & 1.32 \\
\hline $\begin{array}{l}\text { San Luis } \\
\text { Minerales }\end{array}$ & Rio Blanco & Canadá & Oro & $113^{\circ}$ \\
\hline IAMGOLD & $\begin{array}{l}\text { Proyecto de } \\
\text { lanGold }\end{array}$ & Canadá & Oro & $750^{\circ}$ \\
\hline ECSA & $\begin{array}{l}\text { San Carlos } \\
\text { Pasantza }\end{array}$ & China & Cobre & $1.300^{\circ}$ \\
\hline \multicolumn{4}{|c|}{ TOTAL } & 5.117 \\
\hline
\end{tabular}

Elaborado por: SENPLADES / FUENTE: SENPLADES

\section{Generación de empleo}

Los titulares de derechos mineros emplearan personal ecuatoriano en una proporción no menor del $80 \%$.

Se estiman empleos previstos con los proyectos Mi- rador y Fruta del Norte;

Fase de Construcción: 5.600 empleos directos, y 13.100 empleos indirectos.

Fase de Operación: 1.600 empleos directos, y 12.500 empleos Indirectos.

\section{Beneficios e ingresos que genera al estado la minería}

el Estado recuperó la soberanía y control sobre el manejo de los recursos naturales no renovables (incluye la minería), la Constitución y la Ley de Minería establecen que el Estado participa en los beneficios del aprovechamiento de los minerales en un monto que no será inferior a los de la empresa que los explota, en cumplimiento del Art. 408 de la Constitución.

El concesionario también deberá pagar al Estado un porcentaje mínimo del $5 \%$ sobre las ventas del mineral explotado, el 25\% del Impuesto a la Renta, el $12 \%$ de las utilidades, el $12 \%$ del Impuesto al Valor Agregado y el 70\% del Impuesto a los Ingresos Extraordinarios. Todo eso suma lo que se conoce como "Renta Minera".

Los dineros obtenidos por la regalía y las utilidades serán invertidos en proyectos de desarrollo productivo en las comunidades aledañas a los proyectos mineros, para lo cual los Gobiernos Autónomos Descentralizados (Juntas Parroquiales, Municipios) deben presentar proyectos que serán ejecutados por la empresa pública Ecuador Estratégico EP, entidad adscrita al Ministerio Coordinador de Sectores Estratégicos.

\section{Métodos}

Establecer métodos para alcanzar los objetivos y las metas la estrategia y la estandarización. No es posible alcanzar los objetivos y sus metas si no se establecen: planes, programas y proyectos; los métodos (entre ellos los

estándares) para alcanzarlos. En relación a las políticas, consideradas como acciones a ejecutarse por parte del Estado, en el corto, mediano y largo plazos; en la actividad minera de gran escala, como son los objetivos, metas y propuestas que el Estado debe considerar como administrador y dueño de los recursos del subsuelo, necesita la gran inversión y que esta inversión sea de largo plazo por la actividad misma que considera tecnología, ocupación de 
mano de obra o empleo y el cuidado que debe tener una minería responsable con el manejo ambiental; entonces se considera la sustentabilidad de la actividad productiva y alcance de la transformación de materias primas hacia productos con valor agregado para entrar en procesos productivos industrializados. En referencia Al criterio del Dr. Ishikawa: Si se fijan metas y objetivos pero no se acompañan con métodos para alcanzarlos, el control de la calidad acabará por ser un simple ejercicio mental. Entonces la Política Minera debe realizar actividades necesarias para lograr sus objetivos y metas. La metodología definida se estandariza, lo que la convierte en una regla que formará parte de la tecnología y de los procesos de control ambiental.

\section{Resultados}

\section{Aspectos ambientales 0 impactos}

Esto en un punto de vista ambiental se puede clasificar en:

a. Impacto directo o indirecto sobre el medio.

b. Según sea el efecto; a corto o largo plazo.

c. Sea reversible o irreversible.

d. Sea local o externo.

\section{e. Evitable o inevitable}

También se los puede clasificar según el medio que modifica la explotación minera

f. Modificación del suelo

g. Emisión de contaminantes de diferente forma, eje: ruido de explosiones, líquidos, sólidos gases tóxicos, etc.

h. Sobrexplotación de recursos.

i.Modificación del paisaje.

j. Repercusión de la infraestructura.

k. Impacto socioeconómico.

\section{Otros efectos relevantes}

Los efectos ambientales también incluyen la contaminación del suelo ya que, la parte donde van a parar muchos de los desechos tóxicos, líquidos o sólidos es la parte del suelo donde se está ubicada la mina. Esto produce que el suelo deje de ser fértil y se vuelva un terreno árido e infértil que a largo plazo será un terreno sin minerales ni ayuda para que las plantas puedan crecer normalmente.

La mayoría de material que recibe el suelo es material pétreo contaminante, que son los restos de tierra y productos líquidos, químicos tóxicos, que hacen que el suelo pierda minerales.

Otra forma de contaminar el suelo, es por la cantidad de partículas que son depositadas en la atmósfera y pueden bajar por medio de las lluvias, produciendo el fenómeno de "Lluvia Ácida", la cual no solo afecta a un factor en los ecosistemas, sino que afecta a todos los seres, en general, que viven en dicho ambiente.

\section{Efectos de la minería a cielo abierto}

No es mucha la diferencia que hay entre los efectos ocasionados entre cielo abierto y ambiente, ya que los dos efectos dañan principalmente al medio ambiente y a sus fuentes de agua, puesto que un yacimiento de mina debe estar cerca de una fuente de agua. Además de contaminar el ambiente acuífero de las diferentes zonas, también causa el malestar en las poblaciones aledañas a la mina explotada.

\section{Efectos de la minería en salud}

los efectos en la salud más importantes pueden ser:

Respiratorias

Cutáneas

Cancerígenas.

Se inicia haciendo un breve resumen de las clasificaciones de enfermedades respiratorias:

\section{Enfermedades respiratorias}

Referente a la contaminación que puede existir en el área de trabajo y en el ambiente; y, además a la prolongada exposición a los polvos mineros que salen de los yacimientos. El más común es el Azufre. Seguidamente de los polvos normales que ingresan por las vías respiratorias provocando serias afecciones respiratorias. 


\section{Enfermedades cutáneas}

Las diferentes enfermedades cutáneas, se pueden producir por la alta exposición a los rayos UV, el contacto con la inadecuada protección de la piel, los rayo solares entre otros factores que pueden desencadenar una serie de negativos impactos con la irritación, rupturas, resequedad, ampollas y cáncer en la piel.

Muchas son las enfermedades, pero se denominaran las más importantes que atacan a los sistemas cutáneos:

\section{Asbestosis. \\ Talcosis. \\ Baritosis. \\ Estañosis. \\ Calicosis, entre otras más .}

\section{Enfermedades del tipo cancerígenas}

Estos tipos de enfermedad, se originan cuando la exposición a las partículas de polvo ya ha sido superiores a lo normal. La principal parte que ataca es el aparato respiratorio, por lo cual la persona se debilita o muere por problemas respiratorios.

Este tipo de cáncer, provocado por la exposición de las partículas de polvo, es producido por la alta exposición a la sílice y está siendo investigado, ya que, la sílice cristalina es un peligro factor causante de este tipo de cáncer. Aun así solamente con una pequeña cantidad de polvo de sílice se podría desencadenar muchas formas de cáncer en el pulmón. Otros metales pesados que podrían causar el cáncer de pulmón y otros tipos en cuerpo es el níquel y el cromo; siendo el níquel el que puede inducir un tipo de cáncer en los pulmones y los senos peri nasales.

\section{Conflictos sociales}

La minería ha dado una falsa esperanza de riqueza en las comunidades aborígenes, por lo que varias comunidades han llegado al conflicto armado por defender sus yacimientos mineros y no han dejado que los métodos dañinos de las empresas mineras realicen sus trabajos en sus tierras.
A su vez el gobierno, prepara varios planes de minería a gran escala en estos lugares ricos en minerales y metales pesados, tal es el caso del cobre, zinc y otros materiales más abundantes en el país.

En un artículo del Diario "EL COMERCIO" (2012) afirma: "La minería a gran escala se ha convertido en una creciente causa de conflictos sociales y ambientales. La minería en cierto aspecto es rechazada por los habitantes de la población o el lugar donde hay estos minerales importantes para la actividad económica.

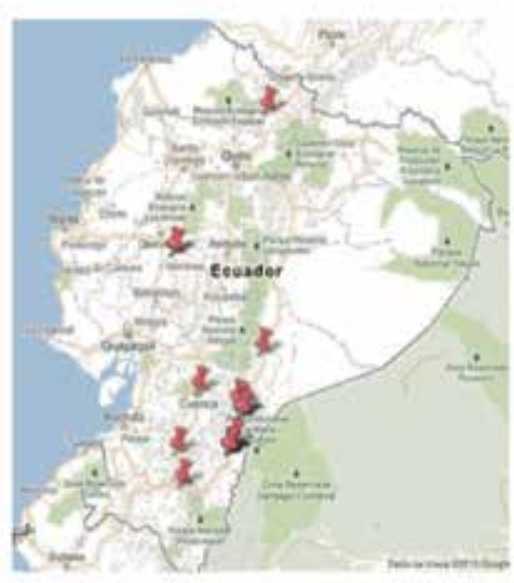

Figura 3. Conflictos Sociales. Fuente: EL COMERCIO” (2012)

Esquema de los lugares donde la minería ha sido rechazada

El país ha enfrentado grandes conflictos por los serios daños que se han hecho al medio ambiente, entre ellos el líquido vital agua y otros efectos biofísicos. Estos son graves problemas de la actividad minera en Ecuador. Tradicionalmente, se consideró un país petrolero, a consecuencia de lo cual la Amazonía está devastada.

En el gobierno de Rafael Correa, se apostó por la minería y Ecuador ocupa el sexto lugar en atracción de inversiones mineras en América Latina. $Y$ las concesiones se concentran en territorios kichwas.

La delegación de ECUARUNARI denunció muchos casos. En la provincia Bolívar se dio una concesión de aguas ilegal que afecta a 72 comunidades que suman más de 40 mil habitantes.

En Zamora Chinchipe hay cientos de concesiones mineras, el gobierno apoya a las empresas transnacionales para explotar oro, cobre y otros metales. El 
Presidente Correa ha firmado un contrato con la empresa canadiense ECOCORRIENTES por 25 años. No hubo un debido proceso para la firma del contrato, se violentó la Constitución.

\section{Caso Kimsakocha}

En la provincia de Azuay hay concesionadas alrededor de 80 mil hectáreas a la minería. Uno de los proyectos es Kimsakocha, que significa Tres Lagunas. Está ubicado en Cuenca, Azuay, al sur de Ecuador, entre los 3000 y 4160 metros sobre el nivel del mar.

La concesión para la explotación de oro, plata y cobre a cielo abierto fue otorgada a la empresa canadiense IAMGOLD el 2001. La inversión para el período 20032011 es de 43 millones de dólares. El tiempo de vida estimado del proyecto es de 25 años y sus reservas bordean los cuatro millones de onzas de oro.

La zona es un páramo de alta biodiversidad que alberga más de treinta lagunas en un sistema hídrico del que surgen los tres ríos principales de los cuatro que tiene Cuenca y sus once micro - cuencas. Para los indígenas Kañari, se trata de un lugar sagrado.

En octubre del 2011 se hizo una consulta comunitaria en las parroquias de Tarqui y Victoria del Portete, aplicando la autodeterminación ancestral, el Convenio 169 de la OIT, la Declaración ONU sobre los Derechos de los Pueblos

Indígenas y la Constitución que garantiza la autonomía. La consulta contó con un Reglamento y la presencia de observadores internacionales.

El primer reto fue lograr la participación de la gente, porque la empresa desarrollaba maniobras de división. Hubo una participación masiva de las mujeres, que cumplieron un importante papel en este proceso. El 94\% dijo no a la minería en Kimsakocha, apostamos por el agua y por la vida. Enviamos las actas a todas las autoridades e instituciones, a la OIT y la ONU. Fue la primera consulta comunitaria en el Ecuador".

El gobierno no aceptó los resultados, alegando que el Estado es el que hace la consulta. Los indígenas argumentaron que las autoridades comunales son autoridades públicas, pero el gobierno no lo aceptó. El Presidente Rafael Correa visitó el lugar. La lucha se había extendido de lo local a lo provincial. La consulta ayudó a la incidencia política nacional e internacional. El caso fue denunciado ante la Comisión de Derechos Humanos de la ONU.

Como consecuencia de esta lucha por el pleno ejercicio de derechos, se abrieron juicios penales a tres dirigentes bajo los cargos de terrorismo y sabotaje. Al no poder probar estos delitos, los acusaron de obstaculizar vías públicas y los sentenciaron a un año de prisión. Las protestas redujeron la pena a ocho días. CAOI Diciembre 11 del 2012, De otra, parte el gobierno de Rafael Correa, presentó la minería como la fuente de recursos para atacar la pobreza y como impulso decisivo al desarrollo, diciendo que no se debe ser mendigos sentado sobre un saco de oro. Es cierto que se creó una mayor fortaleza estatal bajo dicho Gobierno, en que hay un mayor presencia estatal. se aumentaron los tributos y regalías, y se buscó una mejor regulación, lo cual podría conducir a una alivio de la pobreza, sin embargo es dudable que estas medidas sean suficientes para bajar el nivel de conflictos socio ambientales que se encuentra alrededor de las actividades extractivista.

De hecho lo que se ha creado es mayor polarización entre las visiones de la naturaleza y el desarrollo; en varios casos estas posturas se han llevado al extremo de postular casi un chantaje donde se dice que si se pone en riesgo este extractivismo, se perderían los planes sociales y las posibilidades de desarrollo. Las críticas al extractivismo se manejan como si fueran proclamas a favor de la pobreza.Después de haber apoyado a la campaña electoral de Correa, ambientalistas y el movimiento indígena ha recibido palabras cada vez más duras y hasta represión Eduardo Gudynas. 2010 El Gobierno presenta la extracción de recursos naturales como inevitable, y lo único que puede hacer es reducir los impactos sobre la sociedad y la naturaleza, y allí donde no es posible, los grupos locales deberían acrificarpara asegurar un bien mayor para el resto del país Eduardo Gudynas. 2010.

Entonces lo que se presenta, no es un cambio de modelo de desarrollo económico, sino un capitalismo benévolo. No por la tecnología utilizada, sino por el mal manejo de aquellas tecnologías que han hecho que los daños sean impactantes al medio ambiente; primero porque se han hechos malos acuerdos que aparte de dejar pocas ganancias, han dañado el ecosistema sin que haya ni siquiera una indemnización. Fruto de esa falta de compromisos y controles, se dejan como legado los pasivos ambientales. 
Se considera pasivo ambiental a aquellos sitios contaminados por la liberación de materiales o residuos peligrosos, que no fueron remediados oportunamente para impedir la dispersión de contaminantes, pero que implican una obligación de remediación. En esta definición se incluye la contaminación generada por una emergencia que tenga efectos a largo plazo sobre el medio ambiente. (Bertona)

\section{Futuro de la minería}

Según los estudios realizados, sólo el 5\% del territorio nacional ha sido explorado, por lo que no se descarta la existencia de más reservas de minerales en otras zonas del país.

El Plan Nacional de Desarrollo del Sector Minero tiene identificadas 28 zonas de interés. Pero luego de su valoración y tras aplicar métodos estadísticos y geológicos, se seleccionaron 10 zonas de mayor interés, las cuales se concesionarán de la manera indicada y que forman parte del Plan Anual y Plurianual de subasta y remate.

La Ley establece que para otorgar una concesión minera metálica, el Ministerio Sectorial debe convocar a una subasta pública. En el cuadro siguiente se evidencia el listado de los proyectos a desarrollarse.

\section{Proyectos en exploración}

El futuro de la minería en el Ecuador también dependerá del desarrollo de otros proyectos, que se encuentran en su fase de exploración o están cumpliendo con los procesos previstos en la ley vigente. Los proyectos se caracterizan por tener vigentes sus concesiones, estar desarrollados en su mayoría por empresas júnior y requieren entrar en procesos de capitalización y contar con las aprobaciones gubernamentales.

Como establece la Constitución y la Ley de Minería, el desarrollo de los proyectos debe ser con respeto al ambiente, a las comunidades; es decir, estar armonizado con una gestión socio ambiental adecuada que garantice el respeto de los derechos sociales, ambientales, y por otro viabilice la efectiva y sostenida operación de los emprendimientos mineros. Es la única manera mediante la cual la minería seguirá siendo una fuente de desarrollo para el país, en general, y las comunidades, en particular.

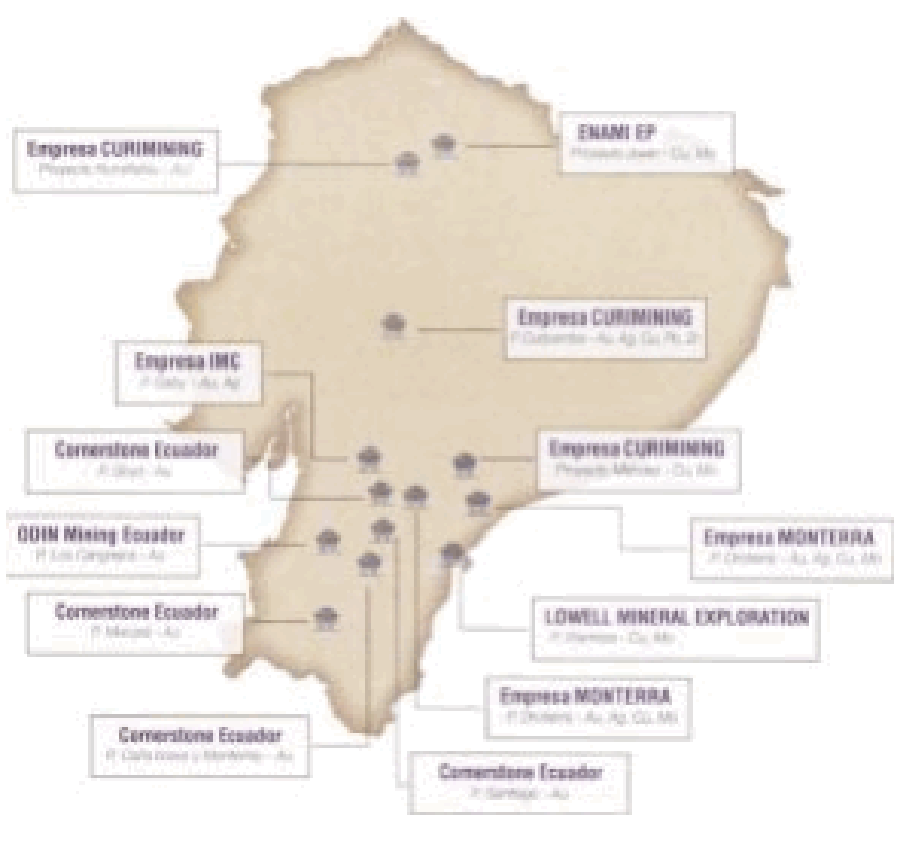

Figura 4. Proyectos de Exploración. Fuente SEMPLADES

Cinco proyectos estratégicos que el gobierno de turno maneja, a través de SENPLADES y del Ministerio; están en el suroriente del país. Mirador (cobre) y Fruta del Norte (oro), se ubican en Zamora Chinchipe. San Carlos Panantza (cobre) está en Morona Santiago, mientras que Río Blanco y Loma Larga (ambos de oro) se encuentran en Azuay.

Los indicados cinco proyectos más el proyecto Llurimagua, ubicado en Imbabura, deberían atraer inversiones por cerca de USD 8000 millones hasta 2024, presentándose un optimismo de la industria minera, pero los desafíos están en mitigar los impactos ambientales y capacitar la mano de obra productiva.

Según el criterio del ministro de Minas, Javier Córdova, e proyecto que está más cerca de empezar a producir es Río Blanco, en el 2018. Ese optimismo es compartido en el sector privado. Rodrigo Izurieta, presidente de la Cámara de Minería del Ecuador; detalla que desde los años 90 se dieron tres etapas para el sector. Entre 1990 y 2006 el país tuvo un marco regulatorio que permitió la llegada de empresas interesadas. (PedroMaldonado, 2017)

Una segunda fase se dio desde el 2006. Fue una etapa restrictiva, con regulaciones estatales muy fuerte. Eso ahuyentó a las empresas mineras. Y desde el 2013 arrancó una fase que, según Izurieta, fue de correcciones y que incluyo la creación del Ministerio de Minas, así como cambios de reglamentos.

Pero, no se debe dejar de lado aspectos importantes 
que generen un equilibrio entre producción y conservación de los recursos mineros sujetos de explotación; hay que considerar y aplicar aspectos de Sostenibilidad, así:

\section{Mecanismos de desarrollo limpio}

Economía Ambiental y Ecológica; que se conjugue en el desarrollo económico y la Sostenibilidad, siendo beneficiarios la Sociedad y la Naturaleza.

Son aquellas inversiones en tecnologías de producción energética eficientes o limpias, realizadas en países en desarrollo. Entre los mecanismos establecidos por el Protocolo de Kioto, los Mecanismos de Desarrollo Limpio (MDL) han sido los que han despertado mayor interés y expectativas, principalmente porque son vistos como un instrumento de convergencia de intereses entre los países industrializados y los países en desarrollo. Se trata de inversiones en lo que se denomina tecnología limpia, esto es, instalaciones que usan energías renovables y/o que usan una tecnología más eficiente que permite producir la misma energía con menos coste ambiental. El artículo 12 del Protocolo de Kioto señala tres objetivos de este mecanismo: Por un lado, el país inversor, hará uso de las Reducciones Certificadas de Emisiones (CER) para alcanzar los objetivos de reducción y limitación de emisiones y, por otro lado, el país receptor de la inversión consigue un desarrollo sostenible a través de la transferencia de tecnologías limpias y, a su vez, contribuye a alcanzar el objetivo último de la Convención de Cambio Climático. (Guerrero, 2005)

\section{Sistemas de ecoeficiencia}

Existen dos elementos principales para la aplicación de programas de eco eficiencia:

La adopción de un cambio en la cultura empresarial

El establecimiento de técnicas adecuadas para promover dichos cambios.

La eco eficiencia, se halla estrechamente ligada al desarrollo sostenible ya que equivale a optimizar tres objetivos: crecimiento económico, equidad social y valor ecológico. Promueve un eco diseño integral de tecnología para reducir la intensidad de uso de materiales y energía durante la producción, además de impulsar la reutilización de insumos a través de procesos de reconversión tecnológica y de reciclaje, aumentando la funcionalidad de los productos y su durabilidad. (Vitalis, 2016)

También se puede entender la eco eficiencia como la relación entre el valor del producto o servicio producido por una empresa y la suma de los impactos ambientales a lo largo de su ciclo de vida: E coeficiencia $=$ valor del producto o servicio $/$ impacto ambiental

\section{Conclusiones}

Se concluye que la actividad minera en el Ecuador, tiene un antecedente histórico de la existencia de yacimientos mineros con potencial industrial, considerando que la presencia de los españoles en América (1492) y años más tarde en lo que ahora es Ecuador, marcó un hito en la historia minera.

En la actualidad el Instituto Nacional de Investigación Geológico-Minero-Metalúrgico (Inigemm) tiene como competencia generar, sistematizar, focalizar y administrar la información geológica en todo el territorio nacional, para promover el desarrollo sostenible y sustentable de los recursos minerales y prevenir la Incidencia de las amenazas geológicas y aquellas ocasionadas por el hombre en apoyo al Ordenamiento Territorial.

Las tres regiones geográficas del país como son: Costa, tiene presencia de minerales no metálicos y placeres auríferos (oro en riberas de los ríos); la región Amazónica, posee reservas de oro, plata, cobre, antimonio y reales expectativas de plomo, zinc y arenas silíceas; y, en la región Sierra, se evidencia la presencia de calizas (materia prima para el cemento), yacimientos de minerales metálicos y no metálicos

La Ley de Minería, vigente desde enero de 2009, estableció una nueva institucionalidad, conformada por: Ministerio Sectorial (Ministerio de Recursos Naturales No Renovables) y otras instituciones inherentes a la rama de actividad minera.

En conclusión, existen riesgos en la actividad minera como los efectos ambientales, incluyen la contaminación del suelo, muchos de los desechos tóxicos, líquidos o sólidos contaminan el suelo donde se está ubicada la mina. Esto produce que el suelo deje de ser fértil y se vuelva un terreno árido e infértil que a largo plazo será un terreno sin minerales ni ayuda para que las plantas puedan crecer normal- 
mente. La mayoría de material que recibe el suelo es material pétreo contaminante, que son restos de tierra y productos líquidos, químicos tóxicos.

Como establece la Constitución y la Ley de Minería, el desarrollo de los proyectos debe ser con respeto al ambiente, a las comunidades; es decir, estar armonizado con una gestión socio ambiental adecuada, que garantice el respeto de los derechos sociales, ambientales, y por otro viabilice la efectiva y sostenible operación de los emprendimientos mineros, bajo mecanismos de Producción más Limpia y de Coeficiencia.

\section{Referencias bibliográficas}

Báez T, Napoleón E: 2005 Ingeniero en Minas, Geólogo, profesor en la Facultad de Geología Minas Petróleos y Ambiental de la Universidad Central, "Rocas y Minerales Industrias en el Ecuador", Quito-Ecuador.

Comunicaciones CAOI; Coordinadora Andina de Organizaciones Indígenas - CAOI Ecua Corriente. Recuperado dehttp://www.corriente.com/corporate/corporate_overview.php

El Comercio, 15 de marzo del 2009. Quito. www.ecuadorminingnews.com

El Comercio, semanario LIDRES del 3 de junio del 2017

Gudynas, Eduardo; Si eres tan progresista ¿Por qué destruyes la naturaleza? Neoextractivismo, izquierda y alternativas en Ecuador Debate 79, Quito, Ecuador, Abril del 2010

IAMGOLD http://www.iamgold.com/

Marqués de Leganés (2005). Mecanismos de desarrollo limpio. Recuperado el 01 de julio de 2017 de: http:// www.ecologistase-naccion.org/article8111.html

Moore, Jenifer ECUADOR: INDIGENOUS RADIO STATION SPARED CLOSURE, Friday, 29 January 2010

ONGVitalis Latinoamérica (2015). Ecoeficiencia. Recuperado el 01 de julio de 2017 de: http://www.vitalis.net/recursos/ecoeficiencia/

Ministerio de Recursos Naturales no Renovables; Minería una fuente para el desarrollo 2da edición Marzo 2012.

Página web de la FISCH
Prensa, El Tiempo. http://www.eltiempo.com.ec/noticias-cuenca/45481-informe-deautopsia-Realizada-a-bosco-wizuma/ Por qué murió Bosco Wissum?Julián Larrea 2010 No todo lo que brilla es oro Camille de Vitry

Pedro Maldonado. (03 de 06 de 2017). Prospectiva Minera. Lideres.

Vitalis. (2016). http://www.vitalis. Obtenido de http://www.vitalis. net/recursos/ecoeficiencia Universo, E. (18 de 12 de 2002). El Sol de Oro del Central pertenece a cultura Tolita. El Universo. 